\title{
Anthocyanin Production and Enzymatic Degradation during the Development of Dark Purple and Lilac Paprika Fruit
}

\author{
Yuji Yamada \\ School of Agriculture, Meiji University, Kawasaki, Kanagawa 214-8571, Japan
}

Masayoshi Nakayama

Institute of Vegetable and Floriculture Science, National Agriculture and Food Research Organization, Tsukuba, Ibaraki 305-8519, Japan

\author{
Hiromitsu Shibata \\ School of Agriculture, Meiji University, Kawasaki, Kanagawa 214-8571, Japan
}

Sanae Kishimoto

Institute of Vegetable and Floriculture Science, National Agriculture and Food Research Organization, Tsukuba, Ibaraki 305-8519, Japan

Takashi Ikeda ${ }^{1}$

School of Agriculture, Meiji University, Kawasaki, Kanagawa 214-8571, Japan

\begin{abstract}
AdDITIONAL INDEX words. Capsicum annuum, carotenoid, chlorophyll, nasunin, peroxidase, transcription factor
Abstract. During development, the fruit of some paprika (Capsicum annuum L.) cultivars shows a change in color from green to dark purple (e.g., 'Mavras') or lilac (e.g., 'Tequila'). However, this purple coloration is rare among paprika cultivars and disappears in ripened fruit, which are red. Therefore, we investigated the mechanism causing this color change in the cultivars Mavras and Tequila to better understand how purple ripened fruit could be generated. High-performance liquid chromatography (HPLC) analyses of the anthocyanin contents of the fruit indicated that anthocyanin was undetectable in green fruit, accumulated in dark purple or lilac ones, and then decreased again in red ones in both cultivars. Furthermore, expressions of most of the analyzed anthocyanin biosynthesis-related genes and genes for their transcription factors increased in dark purple or lilac fruit and decreased in red ones, i.e., it was synchronized with the changes in anthocyanin contents. Furthermore, anthocyanin degradation activity as a result of peroxidases was detected at all stages but increased when the lilac or dark purple color started to fade. Thus, the development of purple coloration is caused by increased anthocyanin biosynthesis, whereas the fading of this coloration is a result of both a decrease in anthocyanin biosynthesis and an increase in anthocyanin degradation. At the ripening stage, the green pigment (chlorophyll) contents decreased, whereas the red pigment (carotenoid, particularly capsanthin) contents increased. However, these timings did not completely coincide with the timing of anthocyanin degradation, suggesting that the content of each pigment is individually regulated, and so purple, green, and red coloration could be freely expressed in mature paprika fruit.
\end{abstract}

Color is one of the most important indicators of fruit quality for consumers and it also decides the market value. Different cultivars of paprika produce different colored fruit, with eight colors being recognized: red, yellow, orange, green, white, brown, purple, and black (Simonne et al., 1997). Among these, purple fruit have particularly good market potential because purple vegetables are rare. However, although purple cultivars change color from green to purple during development, they then become red at maturity (Fig. 1), making the commercial use of purple paprika problematic.

The purple anthocyanin nasunin (delphinidin-3-p-coumaroylrutinoside-5-glucoside) was isolated from eggplant (Solanum melongena L.) peels by Kuroda and Wada (1933). It is also one of the major pigments responsible for the purple coloration of the paprika fruit (Aza-González and Ochoa-Alejo, 2012; Lightbourn

Received for publication 24 Apr. 2019. Accepted for publication 12 June 2019. We thank Kumi Yamanaka and Manami Akai for technical assistance.

${ }^{1}$ Corresponding author. E-mail: agrisys@meiji.ac.jp. et al., 2008). Thus, the change in purple color intensity that occurs in paprika fruit during development appears to be caused by changes in the anthocyanin contents, suggesting that both anthocyanin biosynthesis and degradation are involved in this process.

Anthocyanin biosynthetic activity can be estimated by measuring the expression levels of anthocyanin biosynthesisrelated genes, which are regulated by a complex of transcription factors that are encoded by the $M Y B$, basic helix-loop-helix (bHLH), and WD40-repeat (WDR) genes (Koes et al., 2005; Ramsay and Glover, 2005; Xu et al., 2015). In paprika, the expressions of some anthocyanin biosynthesis-related genes are upregulated by $M Y B$ and $M Y C / b H L H$ (Aguilar-Barragán and Ochoa-Alejo, 2014; Lu et al., 2018; Zhang et al., 2015), and unripe fruit have higher expressions than ripe ones of $M Y B$ in the purple inbred line 5226 (Borovsky et al., 2004) and of anthocyanin biosynthesis-related genes in the purple cultivars Arvol and Uvilla (Aza-González et al., 2013). The enzymatic degradation of anthocyanin has also been detected in plants 


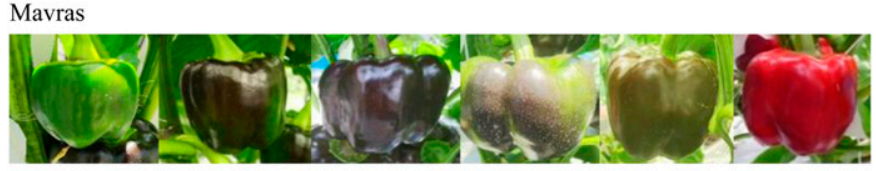

Tequila

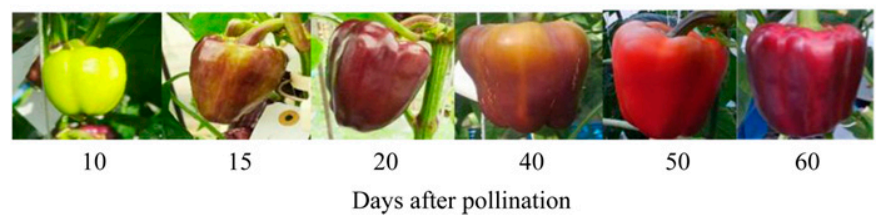

Fig. 1. Fruit of the paprika cultivars Mavras and Tequila at the indicated number of days after pollination.

(Barbagallo et al., 2007; Fang et al., 2015; Vaknin et al., 2005; Zipor et al., 2015), which may involve peroxidases, polyphenol oxidases, and $\beta$-glucosidases (reviewed by Oren-Shamir, 2009).

Based on this information, we investigated the mechanism behind the change in purple coloration in the paprika fruit by examining changes in the anthocyanin biosynthesis and degradation activities in the fruit of the cultivar Mavras, which are dark purple when immature, and Tequila, which are lilac when immature. We also studied the synchrony between content changes in anthocyanins and both chlorophylls (green pigments) and carotenoids (red pigments) during fruit development to determine whether they are regulated by the same mechanism.

\section{Materials and Methods}

Plant materials. The paprika cultivars Mavras and Tequila were obtained from Enza Zaden (Enkhuizen, The Netherlands) and a Japanese distributor, respectively. Seeds of each cultivar were sown on a 72 -cell plug tray $(300 \times 600 \times 50 \mathrm{~mm})$ filled with commercial medium (Yosaku N-150; ZEN-NOU, Tokyo, Japan) on 28 Feb. (Expt. 1) and 1 Sept. (Expt. 2) 2017. After 2 weeks, the seedlings were transplanted into containers $(600 \times$ $400 \times 200 \mathrm{~mm})$ at a density of two seedlings per container and grown hydroponically (EC, $1.2-1.5 \mathrm{mS} \cdot \mathrm{cm}^{-1}$; $\left.\mathrm{pH} 5.6-6.3\right)$ in a mixture of two commercial nutrient solutions (OAT House 1 gou and OAT House 2 gou; OAT Agrio, Osaka, Japan) in a glasshouse at the Ikuta campus of Meiji University (Kawasaki, Japan). To avoid exposure to extreme temperatures, the roof and side windows of the glasshouse were opened when the temperature inside the glasshouse reached $25^{\circ} \mathrm{C}$, the ceiling fan was activated at $30{ }^{\circ} \mathrm{C}$, and a heater was operated when the temperature fell below $12^{\circ} \mathrm{C}$. No other environmental conditions (e.g., relative humidity and light) were measured inside the glasshouse.

Eight plants per cultivar were used in each experiment. Pollination was performed by gently shaking the flowers by hand, and fruit were harvested at 10, 15, 20, 40, 50, and $60 \mathrm{~d}$ after pollination (DAP) for each cultivar (Fig. 1). We sampled $1-2 \mathrm{~g}$ of pericarp from individual different fruit and flashfrozen in liquid nitrogen and stored at $-80{ }^{\circ} \mathrm{C}$.

Quantitative ANALYSES OF ANTHOCYANIN, CINNAMIC ACID DERIVATIVE, AND FLAVONOID CONTENTS. The anthocyanin, cinnamic acid derivative, and flavonoid contents of the fruit were measured following Ikeda et al. (2011) with some modifica- tions. Samples were ground with a mortar and pestle, extracted in six times its volume of $10 \%(\mathrm{v} / \mathrm{v})$ acetic acid overnight at $4{ }^{\circ} \mathrm{C}$, and centrifuged at $12,000 \mathrm{~g}_{\mathrm{n}}$ for $3 \mathrm{~min}$ (CF15RXII; Hitachi, Tokyo, Japan). The supernatant $(10 \mu \mathrm{L})$ was then analyzed on a HPLC system with photodiode array detector (EZChrom Elite; Hitachi) and generic description $4.6 \times 250$ mm column (Inertsil ODS-2; GL Science, Tokyo, Japan). HPLC separation was performed at $40{ }^{\circ} \mathrm{C}$ with a flow rate of $0.8 \mathrm{~mL} \cdot \mathrm{min}^{-1}$ and a linear gradient of $20 \%$ to $100 \%$ solvent B (1.5\% phosphoric acid, $20 \%$ acetic acid, and $25 \%$ acetonitrile) in solvent A (1.5\% phosphoric acid) over $40 \mathrm{~min}$. Absorption spectra were monitored at 220-600 $\mathrm{nm}$ and anthocyanins, cinnamic acid derivatives, and flavonoids were distinguished based on their absorption maxima (525, 330, and $360 \mathrm{~nm}$, respectively). The absorption at each of these wavelengths was used to quantify the amount of each component as an equivalent value of delphinidin glucoside, caffeic acid, and rutin (all from Funakoshi Co., Tokyo, Japan), respectively.

IDENTIFICATION OF ANTHOCYANins. Anthocyanins were extracted with $10 \%(\mathrm{v} / \mathrm{v})$ acetic acid from the pericarps of fruit of 'Mavras' and 'Tequila' at 20 DAP as well as from those of a commercially purchased eggplant of Japanese cultivar. Both the paprika and eggplant extracts were loaded on thin-layer chromatography (TLC) plates (Merck, Darmstadt, Germany) and the plates were developed with $10 \%$ acetic acid or $n$ butanol/acetic acid/distilled water at a 4:1:2 (v/v/v) ratio for $70 \mathrm{~mm}$ from sample spot.

'Tequila' and the Japanese eggplant extracts were analyzed by HPLC (HP1100; Agilent Technologies, Santa Clara, CA) using the same conditions in the EZChrom Elite HPLC system to compare retention time and absorption spectrum of major anthocyanin in each extract. Separately, 'Tequila' and 'Mavras' extracts were analyzed by the EZChrom Elite HPLC system to compare retention time of a major anthocyanin in each extract.

QuANTITATIVE ANALYSES OF CHLOROPHYLL AND CAROTENOID CONTENTS. The chlorophyll and carotenoid contents of the fruit were measured as described by Kishimoto et al. (2007) with some modifications. Samples from individual different fruit were ground in liquid nitrogen with a mortar and pestle, mixed with acetone/diethyl ether/Tris $\cdot \mathrm{HCl}$ buffer $(\mathrm{pH}$ 8.0) [10:30:1 $(\mathrm{v} / \mathrm{v} / \mathrm{v})]$, and centrifuged at $12,000 g_{\mathrm{n}}$ for $3 \mathrm{~min}$. Separate aliquots of the supernatants were then used to analyze the chlorophyll and carotenoid contents. For the carotenoid analysis, the supernatant was first saponified with $10 \%$ methanolic $\mathrm{KOH}$ for $1 \mathrm{~h}$ at $4{ }^{\circ} \mathrm{C}$ in the dark. For both analyses, the supernatant was then evaporated at $37^{\circ} \mathrm{C}$ in a rotary evaporator (N-1000; Tokyo Rikakikai, Tokyo, Japan) with a water bath (SB-1000; Tokyo Rikakikai), the residue was dissolved in acetone, and the pigments were separated by the EZChrome Elite HPLC on YMC column (Carotenoid S-5 $\mu \mathrm{m}, 250 \times$ $4.6 \mathrm{~mm}$; Separation Technology, Sanford, FL). The HPLC analysis conditions for both the chlorophylls and carotenoids were as described in Kishimoto et al. (2007). Pigments were distinguished on the basis of the absorption spectra, with maxima of around $440 \mathrm{~nm}$ for chlorophylls and $480 \mathrm{~nm}$ for carotenoids. The absorption at each of these wavelengths was used to quantify the amount of each component. Chlorophylls and carotenoids in paprika fruit were quantified by drawing a standard curve with the standard.

IDENTIFICATION OF CHLOROPHYLLS AND CAROTENOIDS. Standards of chlorophyll $a$, chlorophyll $b, \beta$-carotene, lutein, 
zeaxanthin, violaxanthin, capsanthin, and capsorubin were purchased from Fujifilm Wako Pure Chemical (Osaka, Japan). These standard samples and the extracted compounds were analyzed by HPLC under the same conditions as described previously, and the retention times and absorption spectra (400-510 nm) were compared.

RNA EXTRACTION AND QUANTITATIVE POLYMERASE CHAIN REACTION (QPCR). Total RNA extraction was performed following the methods of Matsushita et al. (2016) and Okutsu et al. (2018), which were based on the procedure of Reid et al. (2006). Total RNA was extracted in $1 \mathrm{M}$ Tris- $\mathrm{HCl}$ buffer $(\mathrm{pH}$ 8.0) containing $0.5 \mathrm{M}$ ethylenediaminetetraacetic acid (EDTA), $5 \mathrm{M} \mathrm{NaCl}, 2 \%$ cetyltrimethylammonium bromide (Merck), $0.05 \%$ spermidine trihydrochloride (Merck), and 2\% polyvinylpolypyrrolidone (PVPP) (Merck). RNA concentration was measured with a spectrophotometer (NanoDrop 2000; Thermo Fisher Scientific, Waltham, MA). cDNA was then synthesized from the isolated RNA using the PrimeScript RT Reagent Kit with gDNA Eraser (Perfect Real Time; Takara Bio, Shiga, Japan) and was used for qPCR.

The expressions of the following genes were measured by qPCR: the anthocyanin biosynthesis-related genes phenylalanine ammonia-lyase [PAL (DQ229940)], chalcone synthase [CHS (FJ705842)], chalcone isomerase [CHI (FJ705843)], flavanone 3-hydroxylase [F3H (FJ705844)], flavonoid 3' 5' hydroxylase $\left[F 3^{\prime} 5^{\prime} H(\mathrm{FJ} 705845)\right]$, dihydroflavonol 4-reductase $[D F R ;(\mathrm{FJ} 705846)]$, anthocyanidin synthase $[A N S$; (FJ705847)], and UDP glucose: flavonoid 3-O-glucosyltransferase [UFGT; (FJ705848)]; and the transcription factor genes $M Y B$ (AJ608992), bHLH (no accession number), and WDR (no accession number). Specific primer sets for $P A L, F 3^{\prime} 5^{\prime} H$, $A N S, M Y B, b H L H$, and $W D R$ were adopted from AzaGonzález et al. (2013) and Zhang et al. (2015), whereas primer sequences for the other genes were based on sequences contained in the GenBank database and were designed with the Primer-BLAST software (National Center for Biotechnology Information, 2019). The primer sequences are listed in Supplemental Table 1. qPCR was performed in an Applied Biosystems 7300 Real-Time PCR System (Thermo Fisher Scientific) using a PCR protocol of one cycle of denaturation at $95{ }^{\circ} \mathrm{C}$ for $30 \mathrm{~s}$, followed by 50 cycles of denaturation at $94{ }^{\circ} \mathrm{C}$ for $15 \mathrm{~s}$ and annealing/extension at $60{ }^{\circ} \mathrm{C}$ for $60 \mathrm{~s}$. Because Zhang et al. (2015) used ubiquitin as a reference gene, ubiquitin [UBI (no accession number)] was used as a reference gene for calculating relative expression based on the comparative CT method described by Schmittgen and Livak (2008). The following equation was used to investigate relative expression of the target genes with respect to the reference gene:

$$
\begin{gathered}
\Delta \mathrm{Ct}=\mathrm{Ct}(\text { target })-\mathrm{Ct}(\text { reference }), \\
\text { Relative value }=2^{-\Delta \mathrm{Ct}} .
\end{gathered}
$$

qPCR was run for three technical replicates per sample.

Anthocyanin-degrading EnZYMe extraction AND ANTHOCYANIN DEGRADATION ASSAY. Samples were ground in liquid nitrogen with a mortar and pestle and extracted in $10 \mathrm{~mL}$ of enzyme extraction solution modified from that used by Zipor et al. (2015) [20 mm sodium acetate (pH 5), $20 \mathrm{~mm} \mathrm{CaCl}_{2}, 1 \mathrm{~mm}$ phenylmethylsulfonyl fluoride (Fujifilm Wako Pure Chemical), and 2.5\% PVPP (Merck)]. The homogenate was centrifuged at
$12,000 g_{n}$ for $10 \mathrm{~min}$ at $4{ }^{\circ} \mathrm{C}$. The protein concentration in the supernatant was then measured by the Lowry assay (Bio-Rad, Hercules, CA) with a spectrophotometer [NanoDrop 2000 (650 $\mathrm{nm})$ ] using bovine serum albumin as a standard and was considered to represent the protein concentration of crude anthocyanin-degrading enzymes solution (Vaknin et al., 2005).

To determine the anthocyanin degradation activity in each sample, anthocyanins were extracted from the pericarps of 'Mavras' and 'Tequila' fruit in 10\% (v/v) acetic acid and dried in an evaporator, following which the residues were resuspended in $20 \mathrm{~mm}$ sodium acetate buffer $(\mathrm{pH} \mathrm{5)}$. A reaction mixture containing $1 \mathrm{~mL}$ of anthocyanin solution, $1 \mathrm{~mL}$ of anthocyanin-degrading enzymes $\left(1 \mathrm{mg} \cdot \mathrm{mL}^{-1}\right)$, and $1.17 \mu \mathrm{L}$ of $30 \% \mathrm{H}_{2} \mathrm{O}_{2}$ (Fujifilm Wako Pure Chemical) was then divided into two $1-\mathrm{mL}$ aliquots, and $1 \mathrm{~mL}$ of $6 \mathrm{M}$ acetic acid (Fujifilm Wako Pure Chemical) was added to the first sample immediately and to the second sample after $3 \mathrm{~min}$ to stop the reaction. The anthocyanin contents in both samples were then measured by HPLC as described previously. Anthocyanin degradation was determined as the decrease in anthocyanin content per minute at room temperature. Three control reaction mixtures were also used, which contained 1) $1 \mathrm{~mL}$ of anthocyanin solution and $1 \mathrm{~mL}$ of $20 \mathrm{~mm}$ sodium acetate $(\mathrm{pH} \mathrm{5}), 2) 1 \mathrm{~mL}$ of anthocyanin solution and $1 \mathrm{~mL}$ of anthocyanin-degrading enzymes $\left(1 \mathrm{mg} \cdot \mathrm{mL}^{-1}\right)$, 3) $1 \mathrm{~mL}$ of anthocyanin solution and $1.17 \mu \mathrm{L}$ of $30 \% \mathrm{H}_{2} \mathrm{O}_{2}$, and 4) $1 \mathrm{~mL}$ of anthocyanin solution, 1 $\mathrm{mL}$ of anthocyanin-degrading enzymes $\left(1 \mathrm{mg} \cdot \mathrm{mL}^{-1}\right)$ denatured by boiling for $10 \mathrm{~min}$, and $1.17 \mu \mathrm{L}$ of $30 \% \mathrm{H}_{2} \mathrm{O}_{2}$.

STATISTICAL ANALYSIS. Except for zeaxanthin and capsorubin analysis, the significance of differences among the samples was analyzed by the Tukey-Kramer test. In the Tukey-Kramer test, we performed the analysis of variance by using Microsoft Excel software (Microsoft, Redmond, WA) to calculate the $q$ value. $q$ boundary values were determined at the significance level of $P$ $<0.05$. The significance test was performed by comparing the $q$ value with the $q$ boundary value. In zeaxanthin and capsorubin analysis, the significance of differences among the samples was analyzed by Student's $t$ test. We performed Student's $t$ test with a $P$ value of $<0.05$ considered statistically significant.

\section{Results}

Changes in anthocyanin, Cinnamic aCID derivative, AND FLAVONOID CONTENTS. In Expt. 1, no anthocyanins were detected in 'Mavras' at 10 DAP, but they became detectable at 15 DAP (Fig. 2A). The anthocyanin content then reached a maximum at 20 DAP (192.0 $\left.\mathrm{nmol} \cdot \mathrm{g}^{-1}\right)$, following which it decreased to almost half at 40 DAP and became almost undetectable again at 60 DAP. Similar profiles were observed for 'Mavras' in Expt. 2 and 'Tequila' in Expts. 1 and 2 (Fig. 2A and B). Conversely, the contents of cinnamic acid derivatives were highest at 50 DAP, whereas those of flavonoids were highest at 15 DAP (Table 1). Both cinnamic acid derivatives and flavonoids were present at much lower concentrations than anthocyanins at 15-50 DAP.

IDENTIFICATION OF ANTHOCYANINS. Nasunin (delphinidin-3p-coumaroyl-rutinoside-5-glucoside) is a major anthocyanin pigment present in the pericarp of eggplant of a Japanese cultivar and responsible for the purple coloration (Azuma et al., 2008). A fruit of a Japanese eggplant cultivar was commercially purchased, and anthocyanin was extracted from its pericarps in $10 \%(\mathrm{v} / \mathrm{v})$ acetic acid. Thereafter, the extract was used as a standard of nasunin. 
Expt. 1
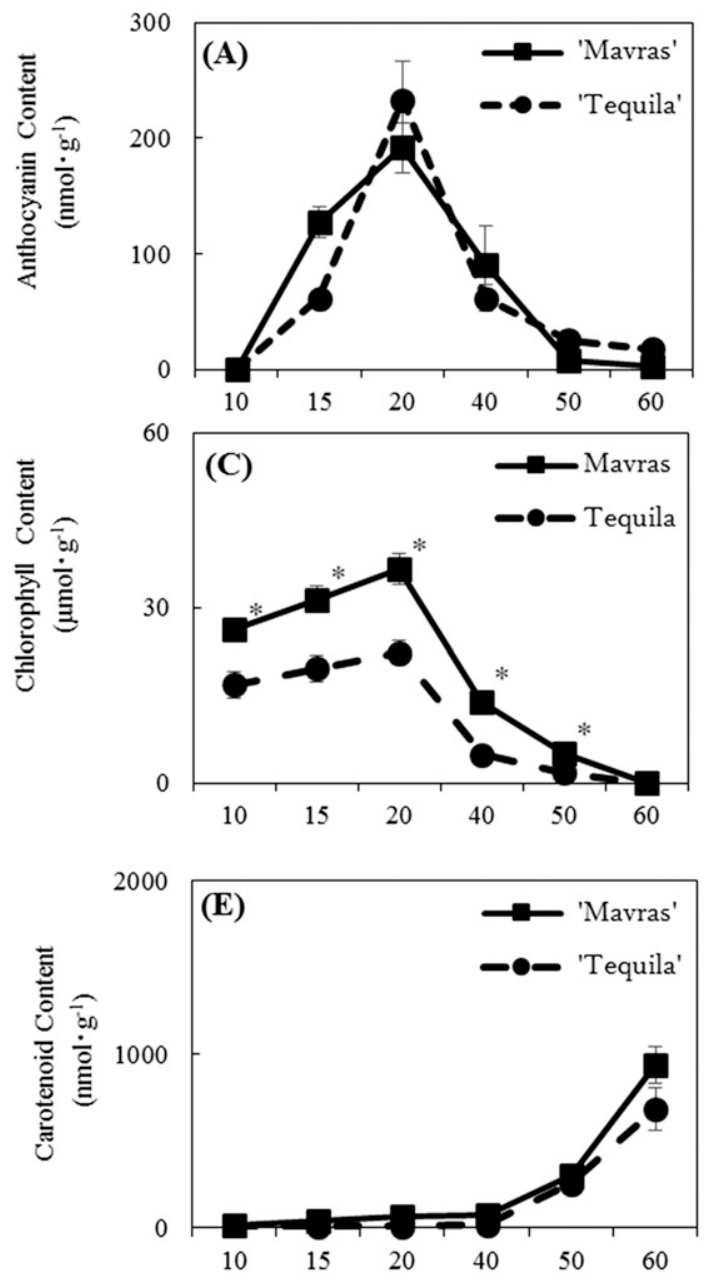

DAP

Fig. 2. Content of (A, B) anthocyanins, $(\mathbf{C}, \mathbf{D})$ chlorophylls, and $(\mathbf{E}, \mathbf{F})$ carotenoids in fruit of the paprika cultivars Mavras and Tequila at the indicated number of days after pollination (DAP) in Expts. 1 (A, C, E) and 2 (B, D, F). Data were recorded on a fresh weight basis and are mean \pm SE (A-B: $n=3$ at 10, 50, and 60 DAP and $n=6$ at 15 , 20, and 40 DAP; C-F: $n=3$ ). Data for the anthocyanin contents were obtained from Table 1, whereas those for the chlorophyll contents are the sum of chlorophylls $a$ and $b$ from Table 2 and those for the carotenoid contents are the sum of $\beta$-carotene, lutein, zeaxanthin, violaxanthin, capsanthin, and capsorubin from Table 3. Asterisks indicate significant differences between 'Mavras' and 'Tequila' fruit at the same DAP (Student's $t$ test at $P<$ $0.05)$.

First, we compared the properties of nasunin of a Japanese eggplant and the anthocyanins of 'Tequila'. In the TLC analyses developed with solvents of $10 \%$ acetic acid and nbutanol/acetic acid/distilled water at a 4:1:2 (v/v/v), the Rf values coincided at 0.47 . In the HP1100 HPLC analyses, the retention times coincided at $17.3 \mathrm{~min}$. In absorption spectra recorded in the HPLC, the $\lambda_{\max }$ values practically coincided $[280,300,310$ (shoulder), and $532 \mathrm{~nm}$ for nasunin; 280, 300, 310 (shoulder), and $530 \mathrm{~nm}$ for the anthocyanins of 'Tequila'). Because of the coincidence of these properties, the main anthocyanins of 'Tequila' were identified to be nasunin, so that it was used as another nasunin standard.

Second, we compared the properties of nasunin and the anthocyanins of 'Mavras'. In the TLC analyses developed with a solvent of $10 \%$ acetic acid, the $\mathrm{Rf}$ values coincided at 0.47 . In the TLC analyses developed with a solvent of n-butanol/acetic acid/distilled water in a ratio of 4:1:2 (v/v/v), the Rf values coincided at 0.47 as well. In EZChrom Elite HPLC analyses, the retention times practically coincided (19.9 min for nasunin and $20.0 \mathrm{~min}$ for the anthocyanins of 'Mavras'). Because of the coincidence of these properties, the main anthocyanins of 'Mavras' were also identified to be nasunin. We noted that nasunin was a unique main anthocyanin present in the pericarp of the fruit of both 'Mavras' and 'Tequila' through all growth stages.

Changes in Chlorophyll CONTENTS. In Expt. 1, chlorophylls were detected in 'Mavras' at 10 DAP at a concentration of 24.1 $\mu \mathrm{mol} \cdot \mathrm{g}^{-1}$ (Fig. 2C). The total chlorophyll contents then slightly increased to reach a maximum concentration of $36.6 \mu \mathrm{mol} \cdot \mathrm{g}^{-1}$ at 20 DAP, following which they decreased to a low level $\left(5.0 \mu \mathrm{mol} \cdot \mathrm{g}^{-1}\right)$ at 50 DAP. Similar profiles were observed for 'Tequila' in Expts. 1 and 2 (Fig. $2 \mathrm{C}$ and D). However, a different profile was found for 'Mavras' in Expt. 2, with the contents slightly decreasing from 10 to 40 DAP and then sharply decreasing at 50 DAP.

Changes In CAROTENOID CONTENTS. In Expt. 1, the carotenoid contents in 'Mavras' remained at a trace level at 10 to $40 \mathrm{DAP}$, following which they slightly increased at 50 DAP and then significantly increased to $924.8 \mathrm{nmol} \cdot \mathrm{g}^{-1}$ at $60 \mathrm{DAP}$ (Fig. 2E). Similar profiles were observed in 'Mavras' in Expt. 2 and in 'Tequila' in Expts. 1 and 2 (Fig. 2E and F).

I D E CHLOROPHYLLS AND CAROTENOIDS. Chlorophylls and carotenoids that were extracted from the fruit of 'Mavras' and 'Tequila' were compared with standard samples. In the HPLC analyses, both the retention times and the $\lambda_{\max }$ values of the compounds that were extracted from these two cultivars matched those of standard samples of chlorophyll $a$, chlorophyll $b, \beta$-carotene, lutein, zeaxanthin, violaxanthin, capsanthin, and capsorubin, resulting in the identification and quantification of these compounds (Supplemental Table 2).

In Expt. 1, contents of chlorophyll $a$ were higher than those of chlorophyll $b$ at 10-50 DAP (Table 2) in 'Mavras' and 'Tequila'. Contents of both chlorophyll $a$ and chlorophyll $b$ in 'Mavras' were higher than those of 'Tequila' at 10-50 DAP. Similar profiles were observed in Expt. 2.

In Expt. 1, the major carotenoids present in 'Mavras' at 60 DAP were capsanthin $(53.4 \%)$, zeaxanthin $(17.3 \%), \beta$-carotene $(14.0 \%)$, and capsorubin (13\%; Table 3$)$. A similar composition 
Table 1. Contents of cinnamic acid derivatives, flavonoids, and anthocyanins (nasunin) in fruits of the paprika cultivars Mavras and Tequila at different numbers of days after pollination (DAP) in Expts. 1 and 2. Data were recorded on a fresh weight basis.

\begin{tabular}{|c|c|c|c|c|c|c|c|}
\hline \multirow[b]{2}{*}{ Pigments } & \multirow[b]{2}{*}{ Cultivar } & \multicolumn{6}{|c|}{ DAP } \\
\hline & & 10 & 15 & 20 & 40 & 50 & 60 \\
\hline & & \multicolumn{6}{|c|}{ Expt. $1\left[\mathrm{pmol} \cdot \mathrm{g}^{-1}(\text { mean } \pm \mathrm{SE})\right]^{\mathrm{z}}$} \\
\hline Cinnamic acid derivatives & Mavras & $2.0 \pm 0.6 b^{y}$ & $4.4 \pm 0.5 \mathrm{~b}$ & $1.8 \pm 0.4 \mathrm{~b}$ & $13.1 \pm 5.6 \mathrm{a}$ & $15.4 \pm 0.5 \mathrm{a}$ & $12.1 \pm 1.8 \mathrm{a}$ \\
\hline \multirow[t]{2}{*}{ Flavonoids } & Mavras & $0.2 \pm 0.1 \mathrm{~b}$ & $0.4 \pm 0.3 \mathrm{~b}$ & $1.3 \pm 0.4 \mathrm{a}$ & $0.2 \pm 0.0 \mathrm{~b}$ & n.d. & n.d. \\
\hline & Tequila & $0.2 \pm 0.0 \mathrm{c}$ & $4.9 \pm 1.3 \mathrm{a}$ & $4.3 \pm 0.6 \mathrm{a}$ & $0.2 \pm 0.1 \mathrm{c}$ & $1.6 \pm 0.3 \mathrm{~b}$ & $1.2 \pm 0.2 \mathrm{~b}$ \\
\hline \multirow[t]{2}{*}{ Anthocyanins } & Mavras & n.d. & $127.4 \pm 12.8 \mathrm{~b}$ & $192.0 \pm 21.8 \mathrm{a}$ & $89.9 \pm 34.3 \mathrm{~b}$ & $8.2 \pm 3.2 \mathrm{c}$ & $2.6 \pm 0.2 \mathrm{c}$ \\
\hline & & \multicolumn{6}{|c|}{ Expt. $2\left[\mathrm{pmol} \cdot \mathrm{g}^{-1}(\right.$ mean $\left.\pm \mathrm{SE})\right]$} \\
\hline \multirow[t]{2}{*}{ Cinnamic acid derivatives } & Mavras & $0.8 \pm 0.1 \mathrm{~b}^{\mathrm{z}}$ & $1.8 \pm 0.6 \mathrm{~b}$ & $1.4 \pm 0.1 \mathrm{~b}$ & $7.0 \pm 2.3 \mathrm{a}$ & $10.4 \pm 5.6 \mathrm{a}$ & $7.0 \pm 0.8 \mathrm{a}$ \\
\hline & Tequila & $0.2 \pm 0.0 \mathrm{c}$ & $0.8 \pm 0.2 \mathrm{c}$ & $1.5 \pm 0.3 \mathrm{c}$ & $8.8 \pm 2.6 \mathrm{~b}$ & $15.4 \pm 3.1 \mathrm{a}$ & $12.1 \pm 1.8 \mathrm{a}$ \\
\hline \multirow[t]{2}{*}{ Flavonoids } & Mavras & $0.1 \pm 0.0 \mathrm{c}$ & $1.8 \pm 0.6 \mathrm{a}$ & $1.0 \pm 0.5 \mathrm{a}$ & $0.9 \pm 0.3 \mathrm{~b}$ & $0.7 \pm 0.1 \mathrm{~b}$ & $0.8 \pm 0.0 \mathrm{~b}$ \\
\hline & Tequila & $0.6 \pm 0.1 \mathrm{c}$ & $5.4 \pm 1.8 \mathrm{a}$ & $2.3 \pm 1.0 \mathrm{a}$ & $3.7 \pm 0.5 \mathrm{a}$ & $2.5 \pm 1.0 \mathrm{ab}$ & $1.6 \pm 0.1 \mathrm{~b}$ \\
\hline Anthocyanins & Mavras & n.d. & $79.4 \pm 12.7 b$ & $165.2 \pm 22.8 \mathrm{a}$ & $53.3 \pm 30.4 b$ & $17.8 \pm 12.5 \mathrm{c}$ & n.d. \\
\hline
\end{tabular}

$\mathrm{z}_{\mathrm{n}}=3$ at 10,50 , and 60 DAP; $\mathrm{n}=6$ at 15,20 , and 40 DAP; $n . d .=$ not detected.

${ }^{\mathrm{y}}$ Different lowercase letters within the same row indicate significant differences (Tukey-Kramer test at $P<0.05$ ).

Table 2. Chlorophyll $a$ and $b$ contents of the fruits of the paprika cultivars Mavras and Tequila at different number of days after pollination (DAP) in Expts. 1 and 2. Data were recorded on a fresh weight basis.

\begin{tabular}{|c|c|c|c|c|c|c|c|}
\hline \multirow[b]{2}{*}{ Pigments } & \multirow[b]{2}{*}{ Cultivar } & \multicolumn{6}{|c|}{ DAP } \\
\hline & & 10 & 15 & 20 & 40 & 50 & 60 \\
\hline & & \multicolumn{6}{|c|}{ Expt. $1\left[\mu \mathrm{mol} \cdot \mathrm{g}^{-1}(\mathrm{mean} \pm \mathrm{SE})\right]^{\mathrm{z}}$} \\
\hline \multirow[t]{2}{*}{ Chlorophyll $a$} & Mavras & $16.7 \pm 1.4 \mathrm{~b}^{\mathrm{y}}$ & $21.0 \pm 2.2 \mathrm{ab}$ & $25.3 \pm 2.9 \mathrm{a}$ & $11.1 \pm 2.9 \mathrm{c}$ & $4.4 \pm 1.6 \mathrm{~d}$ & n.d. \\
\hline & Tequila & $9.5 \pm 1.3 \mathrm{a}$ & $10.4 \pm 1.6 \mathrm{a}$ & $11.3 \pm 1.8 \mathrm{a}$ & $2.7 \pm 0.5 b$ & $0.6 \pm 0.6 \mathrm{c}$ & n.d. \\
\hline \multirow[t]{3}{*}{ Chlorophyll $b$} & Mavras & $7.4 \pm 2.8 \mathrm{a}$ & $9.2 \pm 2.3 \mathrm{a}$ & $11.0 \pm 1.8 \mathrm{a}$ & $2.1 \pm 1.1 \mathrm{~b}$ & $1.1 \pm 0.2 \mathrm{~b}$ & n.d. \\
\hline & Tequila & $4.9 \pm 0.3 \mathrm{~b}$ & $5.9 \pm 0.7 \mathrm{ab}$ & $7.0 \pm 1.0 \mathrm{a}$ & $1.8 \pm 0.2 \mathrm{c}$ & $0.3 \pm 0.2 \mathrm{~d}$ & n.d. \\
\hline & & \multicolumn{6}{|c|}{ Expt. $2\left[\mu \mathrm{mol} \cdot \mathrm{g}^{-1}(\right.$ mean $\left.\pm \mathrm{SE})\right]$} \\
\hline \multirow[t]{2}{*}{ Chlorophyll $a$} & Mavras & $34.6 \pm 2.6 \mathrm{a}$ & $29.9 \pm 2.2 \mathrm{ab}$ & $25.2 \pm 1.8 \mathrm{~b}$ & $19.3 \pm 7.3 \mathrm{c}$ & $4.1 \pm 0.2 \mathrm{~d}$ & n.d. \\
\hline & Tequila & $2.6 \pm 0.6 \mathrm{~b}$ & $4.3 \pm 1.0 \mathrm{a}$ & $6.1 \pm 1.4 \mathrm{a}$ & $0.4 \pm 0.1 \mathrm{~b}$ & $0.2 \pm 0.0 \mathrm{~b}$ & n.d. \\
\hline \multirow[t]{2}{*}{ Chlorophyll $b$} & Mavras & $11.3 \pm 3.4 \mathrm{a}$ & $11.0 \pm 2.8 \mathrm{a}$ & $10.7 \pm 2.2 \mathrm{a}$ & $10.1 \pm 3.5 \mathrm{a}$ & $2.0 \pm 0.9 \mathrm{~b}$ & n.d. \\
\hline & Tequila & $0.8 \pm 0.1 \mathrm{a}$ & $1.1 \pm 0.3 \mathrm{a}$ & $1.3 \pm 0.5 \mathrm{a}$ & $0.1 \pm 0.0 \mathrm{~b}$ & $0.1 \pm 0.0 \mathrm{~b}$ & n.d. \\
\hline
\end{tabular}

${ }_{\mathrm{z}}=3 ;$ n.d. $=$ not detected.

${ }^{\mathrm{y}}$ Different lowercase letters within the same row indicate significant differences (Tukey-Kramer test at $P<0.05)$.

of pigments was also found in 'Tequila' at 60 DAP in Expt. 1, and the same four compounds were the major carotenoids in both cultivars at 60 DAP in Expt. 2. Thus, the developing fruit of both cultivars showed similar changes in pigment contents in both experiments.

EXPRESSIONS OF ANTHOCYANIN BIOSYNTHESIS-RELATED GENES AND TRANSCRIPTION FACTOR GENES. In both experiments, 'Mavras' and 'Tequila' showed similar changes in the expression profiles for all of the analyzed genes (Figs. 3 and 4). All genes except WDR showed increased expression levels from 10 DAP to reach a maximum at 15 or 20 DAP, following which their expressions decreased to almost undetectable levels at 40 to 60 DAP.

Anthocyanin Degradation. No anthocyanin degradation was detected in the control solution containing only anthocyanin (data not shown). For both cultivars, anthocyanin degradation was significantly higher in the presence of both enzymes extracted from the pericarps of the fruit at $40 \mathrm{DAP}$ and $\mathrm{H}_{2} \mathrm{O}_{2}$ than in the presence of the enzyme extract alone, $\mathrm{H}_{2} \mathrm{O}_{2}$ alone, or boiled enzyme extract mixed with $\mathrm{H}_{2} \mathrm{O}_{2}$ (Fig. 5). Anthocyanin degradation in the presence of both $\mathrm{H}_{2} \mathrm{O}_{2}$ and enzyme extract from the fruit remained almost constant at 10 to 20 DAP, increased at 40 DAP, and then leveled off at 50 and 60 DAP for both cultivars in both experiments (Fig. 6).

\section{Discussion}

In this study, we detected the anthocyanin nasunin in the fruit of two paprika cultivars Mavras and Tequila, supporting the findings of previous studies on purple paprika cultivars (Aza-González and Ochoa-Alejo, 2012; Lightbourn et al., 2008). In addition, we found that the difference in coloration depth between these two cultivars could be explained by the higher chlorophyll content in the dark purple fruit of 'Mavras' than that in the lilac fruit of 'Tequila', as shown by Lightbourn et al. (2008). At 10 to 20 DAP, the orange pigment $\beta$-carotene and the yellow pigments violaxanthin and lutein were detected in both cultivars, whereas the red pigments capsanthin and capsorubin and the yellow pigment zeaxanthin were not (Table 3). Similarly, Lightbourn et al. (2008) showed that the violet fruit of the true-breeding paprika genotype G05C74-12 did not contain capsanthin or capsorubin. By contrast, at 40, 50, and 60 DAP, the fruit of both cultivars analyzed in this study accumulated capsanthin, with this becoming the main carotenoid by 60 DAP. These findings indicate that complex changes in the contents of nasunin, chlorophylls, and carotenoids determine the color changes in the developing fruit of these paprika cultivars. At 10 DAP, green fruit contained chlorophylls but no anthocyanins and low levels of carotenoids; at 15 and 20 DAP, the fruit were dark purple or lilac because of both nasunin and chlorophylls; and at 40 to 60 DAP, fruit of both cultivars became red because of a decrease in the anthocyanin and chlorophyll contents and the accumulation of carotenoids, particularly capsanthin. 
Table 3. Carotenoid contents of the fruits of the paprika cultivars Mavras and Tequila at different number of days after pollination (DAP) in Expts. 1 and 2. Data were recorded on a fresh weight basis.

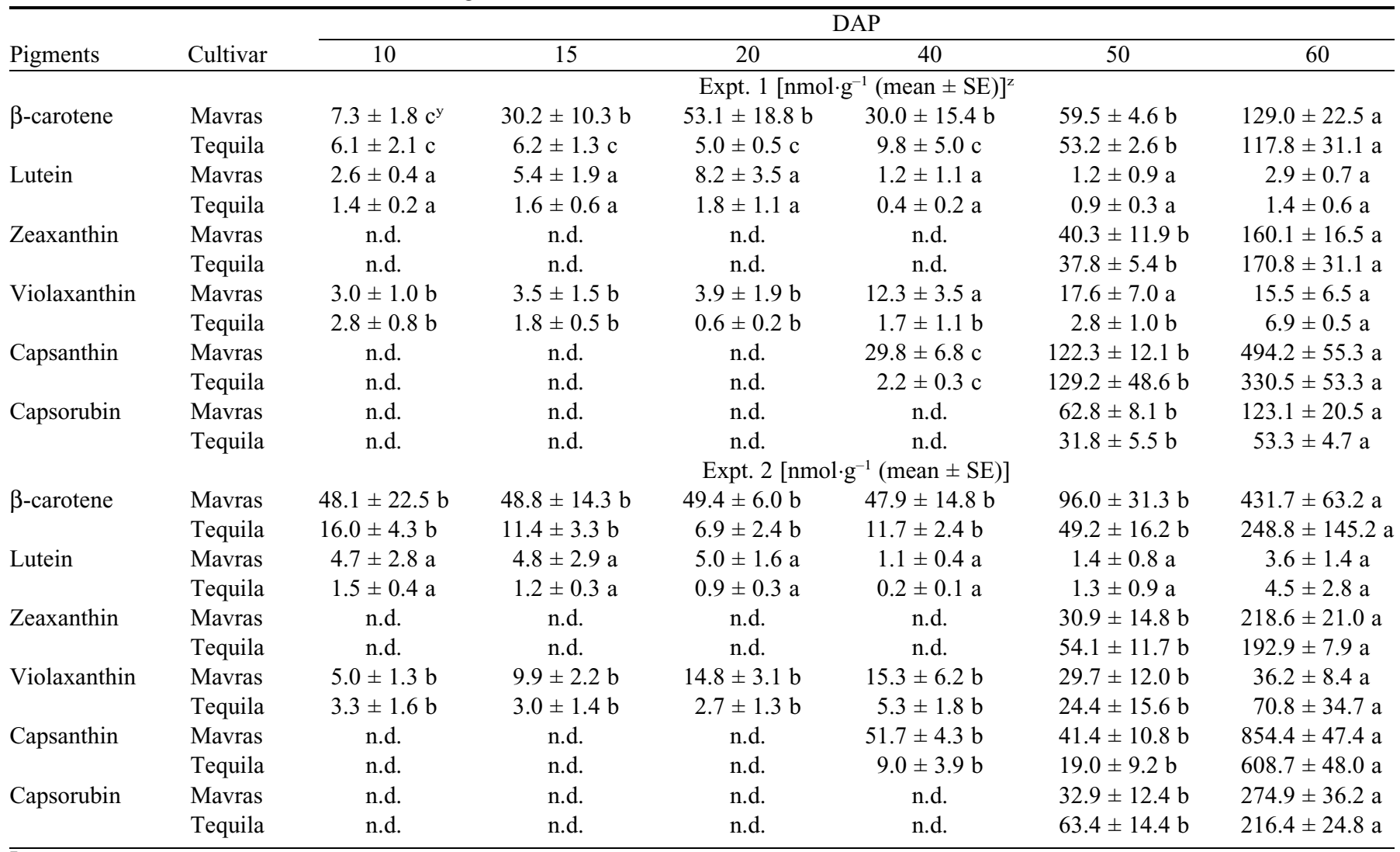

${ }_{\mathrm{n}}=3 ;$ n.d. $=$ not detected.

${ }^{\mathrm{y}}$ Different lowercase letters within the same row indicate significant differences (Tukey-Kramer test for $\beta$-carotene, lutein, violaxanthin, and capsanthin; Student's $t$ test for zeaxanthin and capsorubin; $P<0.05$ for both tests).

In addition, the expressions of anthocyanin biosynthesisrelated genes in the fruit of 'Mavras' and 'Tequila' increased during the unripe stage but then drastically decreased during the ripe stage, which agrees with previous findings for the purple paprika cultivars Arvol and Uvilla (Aza-González et al., 2013). These results suggest that anthocyanin is only synthesized during the unripe stage in purple paprika cultivars. Furthermore, the finding that cinnamic acid derivatives and flavonoids were present at lower concentrations than nasunin (Table 1) indicates that nasunin is biosynthesized without the accumulation of related compounds positioned upstream in the biosynthetic pathway.

It is understood that a complex of the transcription factors $M Y B, b H L H$, and $W D R$ is required for the expression of anthocyanin biosynthesis-related genes. It has previously been demonstrated that lack of any of these transcription factors inhibits anthocyanin biosynthesis in several Capsicum spp. (Aguilar-Barragán and OchoaAlejo, 2014; Lu et al., 2018; Stommel et al., 2009; Zhang et al., 2015), and our data supported this (Figs. 3 and 4). Anthocyanin biosynthesis-related genes were expressed and anthocyanin was biosynthesized, resulting in an increase in anthocyanin contents in the fruit at 15 and 20 DAP, so that $M Y B, b H L H$, and $W D R$ were possibly expressed at sufficient levels at these stages. Under the constitutive expression of $W D R$, the expressions of the anthocyanin biosynthesis-related genes increased with increasing expressions of $M Y B$ and $b H L H$ at 15 or 20 DAP and ceased with decreasing expressions of $M Y B$ and $b H L H$ after 40 DAP. We suggest that $M Y B$ and $b H L H$ may positively regulate the transcription of anthocyanin biosynthesis-related genes in the paprika fruit.

Liu et al. (2018) recently proposed that anthocyanins are degraded by peroxidases in solanaceous plants, using anthocyanin degradation in Brunfelsia calycina Hook. flowers as an example (Vaknin et al., 2005; Zipor et al., 2015). However, to the best of our knowledge, the enzymatic degradation of anthocyanins in the fruit of solanaceous crops, such as paprika, tomato (Solanum lycopersicum L.), and eggplant, has not previously been studied (Sakamura and Obata, 1963), and the suggestion of Liu et al. (2018) has not been tested. In the present study, we found that anthocyanin degradation was highest in the presence of both enzyme extract and $\mathrm{H}_{2} \mathrm{O}_{2}$ (Fig. 5). Fang et al. (2015) and Zipor et al. (2015) argued that peroxidase requires $\mathrm{H}_{2} \mathrm{O}_{2}$ and that polyphenol oxidase requires $\mathrm{O}_{2}$ for the anthocyanin degradation reaction. Furthermore, Barbagallo et al. (2007) showed that $\beta$-glucosidase hydrolyzes anthocyanin. However, this enzyme could not be concerned with deletion of coloration in plant tissues because this reaction generates anthocyanidin, i.e., a chromophore of the anthocyanin and could not delete coloration alone. Therefore, it is likely that anthocyanin degradation in purple paprika fruit is mediated by peroxidases. 

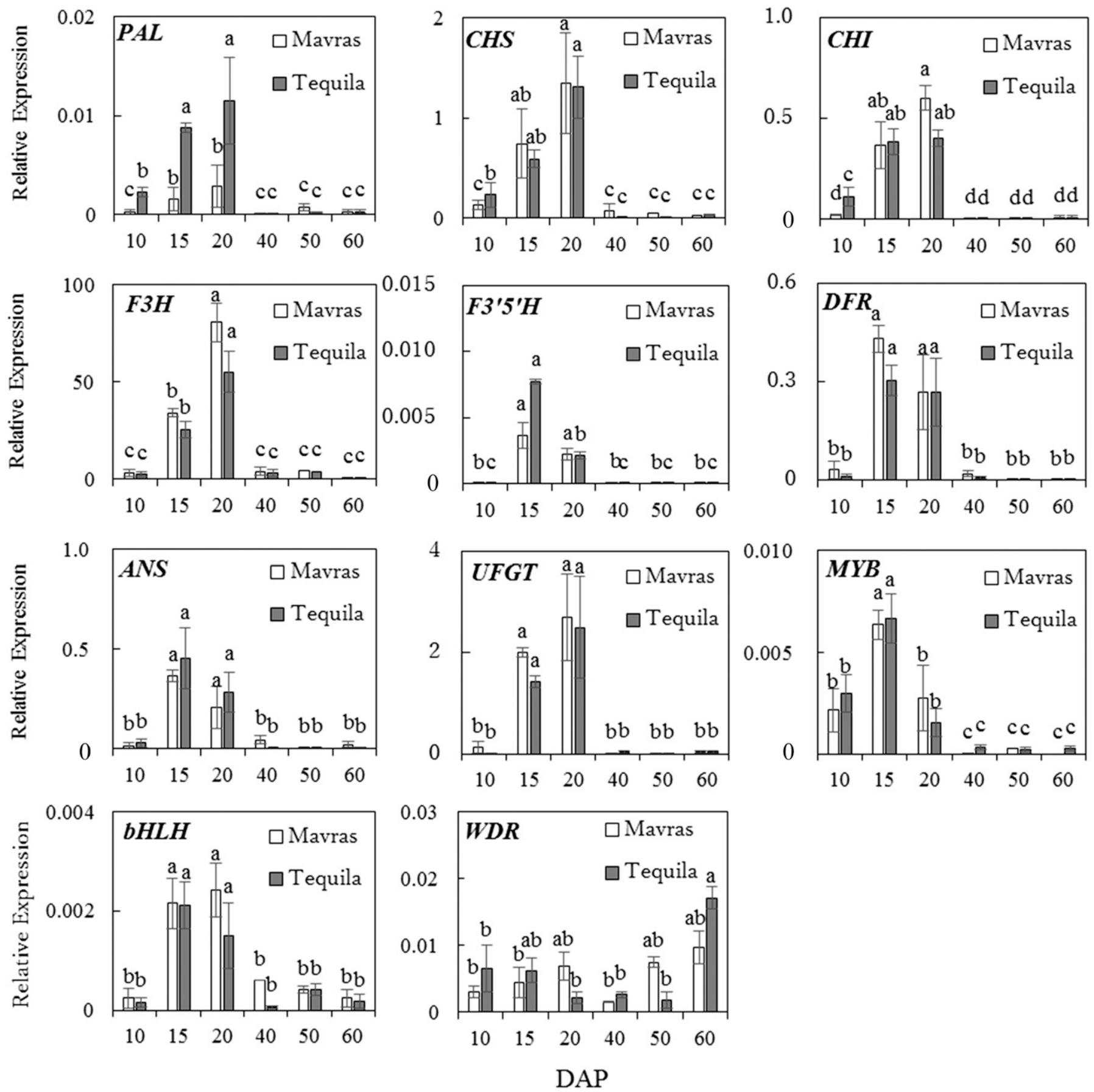

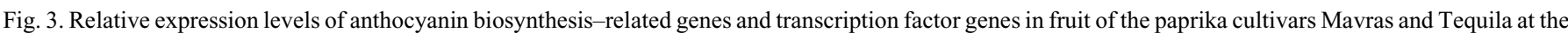
indicated numbers of days after pollination (DAP) in Expt. 1. Data are means $\pm \mathrm{SE}(\mathrm{n}=3$ at 10, 50 , and 60 DAP; $\mathrm{n}=6$ at 15,20 , and 40 DAP). Different letters indicate significant differences among DAPs for each cultivar (Tukey-Kramer test, $P<0.05$ ). $P A L=$ phenylalanine ammonia-lyase, $C H S=$ chalcone synthase, $C H I=$ chalcone isomerase, $F 3 H=$ flavanone 3-hydroxylase, $F 3^{\prime} 5^{\prime} H=$ flavonoid $3^{\prime} 5^{\prime}$-hydroxylase, $D F R=$ dihydroflavonol 4-reductase, $A N S=$ anthocyanidin synthase, $U F G T=$ UDP glucose: flavonoid 3-O-glucosyltransferase, $b H L H=$ basic helix-loop-helix, and $W D R=$ WD40-repeat.

The anthocyanin content of plant tissues and organs is controlled by the anthocyanin turnover, as demonstrated for mature flowers of Petunia $\times$ hybrid Vilm., mustard seedlings (Sinapis alba L.), and grape fruit cell cultures (Vitis vinifera L. cv. Gamay Red) (Jonsson et al., 1984; Sinilal et al., 2011; Zenner and Bopp, 1987). Our analysis revealed that at 15 and 20 DAP, the anthocyanin content of the paprika fruit increased and the fruit turned purple, despite the degradation of anthocyanins by peroxidases, because of increased expressions of the MYB and $b H L H$ genes, which upregulated the expressions of anthocyanin biosynthesis-related genes. However, at 40 to $60 \mathrm{DAP}$, the purple color faded because of the high anthocyanin degradation activity and the decreased expressions of the $M Y B$ and $b H L H$ genes resulting in reduced expressions of the anthocyanin biosynthesis-related genes. 

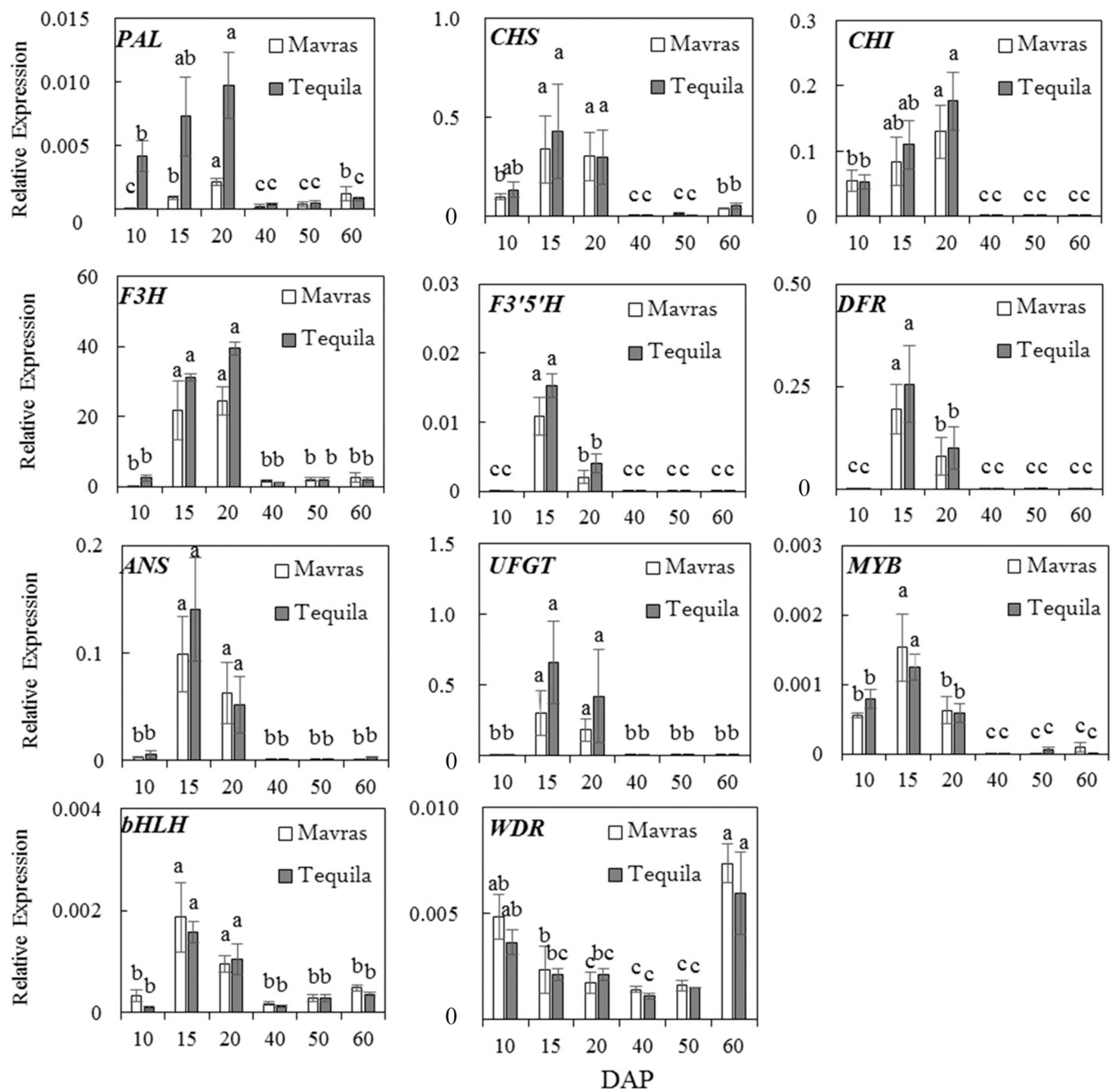

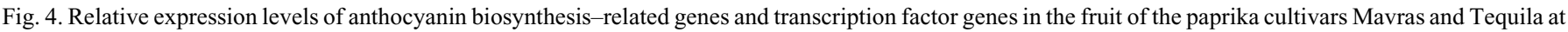
the indicated number of days after pollination (DAP) in Expt. 2. See Fig. 3 for additional details.

Furthermore, the contents of green pigments (chlorophylls) decreased and the contents of red pigments (carotenoids, particularly capsanthin) increased at the ripening stage. However, these timings did not completely coincide with the timing of anthocyanin degradation. At 40 DAP, when expression of the anthocyanin biosynthesis-related genes $M Y B$ and $b H L H$ had decreased and anthocyanin degradation activity had increased, the chlorophyll contents had not fully declined and the carotenoid contents had not yet increased. Therefore, it appears that the content of each pigment is individually regulated, suggesting that each single, double, and triple color combina- tion of purple, green, and/or red could be freely expressed in the mature fruit of paprika.

The first step toward breeding paprika cultivars with purple fruit at the ripe stage is lowering anthocyanin degradation or a continued expression of the anthocyanin regulatory genes (MYB and $b H L H)$ throughout the ripening process, as this would allow the synthesized anthocyanin content to be retained. One effective method for achieving this may be to screen for cultivars with a lower degradation activity at the ripening stage among the general cultivars that are currently grown. By crossing such fruit cultivars with a lower anthocy- 


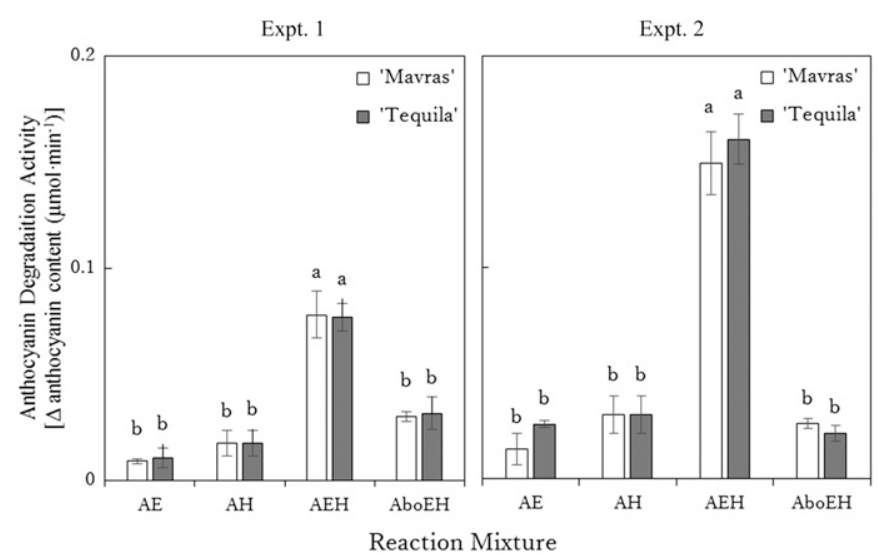

Fig. 5. Anthocyanin degradation by enzyme extracts from the fruit of the paprika cultivars Mavras and Tequila. Reaction mixture contained anthocyanin and enzyme extract from the pericarps of the paprika fruit at $40 \mathrm{~d}$ after pollination (AE); anthocyanin and $\mathrm{H}_{2} \mathrm{O}_{2}(\mathrm{AH})$; anthocyanin, enzyme extract, and $\mathrm{H}_{2} \mathrm{O}_{2}$ (AEH); or anthocyanin, boiled enzyme extract, and $\mathrm{H}_{2} \mathrm{O}_{2}$ (AboEH). $\Delta$ anthocyanin content is the difference in anthocyanin content before and after the reaction. Data are means $\pm \mathrm{SE}(\mathrm{n}=3$ for $\mathrm{AE}, \mathrm{AH}$, and $\mathrm{AboEH} ; \mathrm{n}=6$ for $\mathrm{AEH})$. Different letters indicate significant differences among the reaction mixtures for the same cultivar (Tukey-Kramer test at $P<0.05$ ).

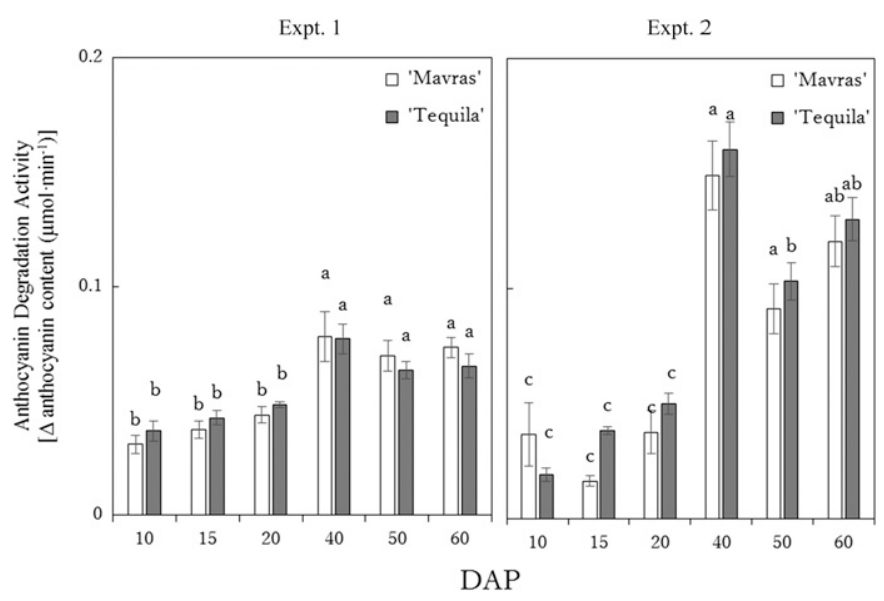

Fig. 6. Anthocyanin degradation by enzyme extracts from the fruit of the paprika cultivars Mavras and Tequila in the presence of $\mathrm{H}_{2} \mathrm{O}_{2}$ at different number of days after pollination (DAP) in Expts. 1 and 2. Data are means $\pm \mathrm{SE}$ $(\mathrm{n}=3$ at 10,15 , and $20 \mathrm{DAP} ; \mathrm{n}=6$ at 40,50 , and 60 DAP). $\Delta$ anthocyanin content is the difference in anthocyanin content before and after the reaction. Different letters indicate significant differences among DAP for each cultivar (Tukey-Kramer test at $P<0.05$ ).

anin degradation activity at the ripening stage, it is expected to grow cultivars with fruit that develop purple color even at the completely ripened stage.

\section{Literature Cited}

Aguilar-Barragán, A. and N. Ochoa-Alejo. 2014. Virus-induced silencing of $M Y B$ and $W D 40$ transcription factor genes affects the accumulation of anthocyanins in chili pepper fruit. Biol. Plant. 58:567-574.

Aza-González, C., L. Herrera-Isidrón, H.G. Núñez-Palenius, O.M. De La Vega, and N. Ochoa-Alejo. 2013. Anthocyanin accumulation and expression analysis of biosynthesis-related genes during chili pepper fruit development. Biol. Plant. 57:4955 .
Aza-González, C. and N. Ochoa-Alejo. 2012. Characterization of anthocyanins from fruits of two Mexican chili peppers (Capsicum annuиm L.). J. Mex. Chem. Soc. 56:149-151.

Azuma, K., A. Ohyama, K. Ippoushi, T. Ichiyanagi, A. Takeuchi, T. Saito, and H. Fukuoka. 2008. Structures and antioxidant activity of anthocyanins in many accessions of eggplant and its related species. J. Agr. Food Chem. 56:10154-10159.

Barbagallo, R.N., R. Palmeri, S. Fabiano, P. Rapisarda, and G. Spagna. 2007. Characteristic of $\beta$-glucosidase from Sicilian blood oranges in relation to anthocyanin degradation. Enzyme Microb. Technol. 41:570-575.

Borovsky, Y., M. Oren-Shamir, R. Ovadia, W. De Jong, and I. Paran. 2004. The $A$ locus that controls anthocyanin accumulation in pepper encodes a $M Y B$ transcription factor homologous to Anthocyanin2 of Petunia. Theor. Appl. Genet. 109:23-29.

Fang, F., X.L. Zhang, H.H. Luo, J.J. Zhou, Y.H. Gong, W.J. Li, Z.W. Shi, Q. He, Q. Wu, L. Li, L.L. Jiang, Z.G. Cai, M. Oren-Shamir, Z.Q. Zhang, and X.Q. Pang. 2015. An intracellular laccase is responsible for epicatechin-mediated anthocyanin degradation in litchi fruit pericarp. Plant Physiol. 169:2391-2408.

Ikeda, T., N. Suzuki, M. Nakayama, and Y. Kawakami. 2011. The effects of high temperature and water stress on fruit growth and anthocyanin content of pot-grown strawberry (Fragaria $\times$ ananassa Duch. cv. 'Sachinoka') plants. Environ. Control Biol. 49:209-215.

Jonsson, L.M.V., W.E. Donker-Koopman, and A.W. Schram. 1984. Turnover of anthocyanins and tissue compartmentation of anthocyanin biosynthesis in flowers of Petunia hybrid. J. Plant Physiol. 115:29-37.

Kishimoto, S., K. Sumitomo, M. Yagi, M. Nakayama, and A. Ohmiya. 2007. Three routes to orange petal color via carotenoid components in 9 Compositae species. J. Jpn. Soc. Hort. Sci. 76:250-257.

Koes, R., W. Verweij, and F. Quattrocchio. 2005. Flavonoids: A colorful model for the regulation and evolution of biochemical pathways. Trends Plant Sci. 10:236-242.

Kuroda, C. and M. Wada. 1933. The colouring matter of eggplant (Nasu). Proc. Imperial Acad. 9:51-52.

Lightbourn, G.J., R.J. Griesbach, J.A. Novotny, B.A. Clevidence, D.D. Rao, and J.R. Stommel. 2008. Effects of anthocyanin and carotenoid combinations on foliage and immature fruit color of Capsicum annuum L. J. Hered. 99:105-111.

Liu, Y., Y. Tikunov, R.E. Schouten, L.F.M. Marcelis, R.G.F. Visser, and A. Bovy. 2018. Anthocyanin biosynthesis and degradation mechanisms in Solanaceous vegetables: A review. Front Chem. 6:52. Lu, B.Y., G.X. Cheng, Z. Zhang, J.T. Sun, M. Ali, Q.L. Jia, L. De-Xu, Z.H. Gong, and D.W. Li. 2018. CaMYC, a novel transcription factor, regulates anthocyanin biosynthesis in color-leaved pepper (Capsicum annuum L.). J. Plant Growth Regulat. 37:1-12.

Matsushita, K., T. Sakayori, and T. Ikeda. 2016. The effect of high air temperature on anthocyanin concentration and the expressions of its biosynthetic genes in strawberry 'Sachinoka'. Environ. Control Biol. 54:101-107.

National Center for Biotechnology Information. 2019. PrimerBLAST. 5 Feb. 2017. <https://www.ncbi.nlm.nih.gov/tools/primerblast/index.cgi?LINK_LOC=BlastHome $>$.

Okutsu, K., K. Matsushita, and T. Ikeda. 2018. Differential anthocyanin concentrations and expression of anthocyanin biosynthesis genes in strawberry 'Sachinoka' during fruit ripening under hightemperature stress. Environ. Control Biol. 56:1-6.

Oren-Shamir, M. 2009. Does anthocyanin degradation play a significant role in determining pigment concentration in plants? Plant Sci. 177:310-316.

Ramsay, N.A. and B.J. Glover. 2005. MYB-bHLH-WD40 protein complex and the evolution of cellular diversity. Trends Plant Sci. 10:63-70.

Reid, K.E., N. Olsson, J. Schlosser, F. Peng, and S.T. Lund. 2006. An optimized grapevine RNA isolation procedure and statistical determination of reference genes for real-time RT-PCR during berry development. BMC Plant Biol. 6:27. 
Sakamura, S. and Y. Obata. 1963. Anthocyanase and anthocyanins occurring in eggplant, Solanum melongena L. Agr. Biol. Chem. 27:121-127.

Schmittgen, T.D. and K.J. Livak. 2008. Analyzing real-time PCR data by the comparative $\mathrm{C}_{\mathrm{T}}$ method. Nat. Protoc. 3:1101-1108.

Simonne, A.H., E.H. Simonne, R.R. Eitenmiller, H.A. Mills, and N.R. Green. 1997. Ascorbic acid and provitamin A contents in unusually colored bell peppers (Capsicum annuum L.). J. Food Compos. Anal. 10:299-311.

Sinilal, B., R. Ovadia, A. Nissim-Levi, A. Perl, M. CarmeliWeissberg, and M. Oren-Shamir. 2011. Increased accumulation and decreased catabolism of anthocyanins in red grape cell suspension culture following magnesium treatment. Planta 234:61-71.

Stommel, J.R., G.J. Lightbourn, B.S. Winkel, and R.J. Griesbach. 2009. Transcription factor families regulate the anthocyanin biosynthetic pathway in Capsicum annuum. J. Amer. Soc. Hort. Sci. 134:244-251.
Vaknin, H., A. Bar-Akiva, R. Ovadia, A. Nissim-Levi, I. Forer, D. Weiss, and M. Oren-Shamir. 2005. Active anthocyanin degradation in Brunfelsia calycina (yesterday-today-tomorrow) flowers. Planta 222:19-26.

Xu, W., C. Dubos, and L. Lepiniec. 2015. Transcriptional control of flavonoid biosynthesis by MYB-bHLH-WDR complexes. Trends Plant Sci. 20:176-185.

Zenner, K. and M. Bopp. 1987. Anthocyanin turnover in Sinapis alba L. J. Plant Physiol. 126:475-482.

Zhang, Z., D.W. Li, J.H. Jin, Y.X. Yin, H.X. Zhang, W.G. Chai, and Z.H. Gong. 2015. VIGS approach reveals the modulation of anthocyanin biosynthetic genes by $C a M Y B$ in chili pepper leaves. Front. Plant Sci. 6:500.

Zipor, G., P. Duarte, I. Carqueijeiro, L. Shahar, R. Ovadia, P. TeperBamnolker, D. Eshel, Y. Levin, A. Doron-Faigenboim, M. Sottomayor, and M. Oren-Shamir. 2015. In planta anthocyanin degradation by a vacuolar class III peroxidase in Brunfelsia calycina flowers. New Phytol. 205:653-665. 
Supplemental Table 1. Primers used for quantitative polymerase chain reaction (qPCR).

\begin{tabular}{lll}
\hline Gene $^{z}$ & \multicolumn{1}{c}{ Forward sequence $\left(5^{\prime}-3^{\prime}\right)$} & Reverse sequence $\left(5^{\prime}-3^{\prime}\right)$ \\
\hline PAL & ATTGATTTTGCAAGAAATCAATTC \\
CHS & GTTGCTTTGCTGGTGGAACC & GCTCCACTTTAGCCCCAC \\
CHI & AGTTCCTGGCACTGGGAATG & CACTTGGGCCACGGAAAGTA \\
F3H & GCCAAGGAGCAGCAGATACA & CTTTGCGGCAGGTGAAACTC \\
F3' $5^{\prime} \mathrm{H}$ & GATGGGGTGGCCGGTGATTG & TTCCTCAATGGGCATGGATTC \\
DFR & GCCATTCAAGGCTGTCAAGG & GCCACCACAACGCGCTCG \\
ANS & CAAATGCCCACAACCAGAACTAGC \\
UFGT & ACCCCTATTGGTTGTGAAGCC & AACATTCCCCTGACCGTTGG \\
MYB & AGATTGCCGGGAAGAACAGCAAAC & CGCACTTTGCAGTTACCCACTTTC \\
bHLH & CAATGGAGCTATAAAGACTAGGAA & ACCTATTTCTCCTCTGCCTC \\
WDR & GTGTGAATGCTATTGCTTGG & TTGCACTTGATGAGAAGGTCCGAG \\
UBIOUITIN & TGTCCATCTGCTCTCTGTTG & GGAAAAGAGAAAGAAACACACATG \\
\hline
\end{tabular}

${ }^{\mathrm{z} P A L}=$ phenylalanine ammonia-lyase; $C H S=$ chalcone synthase; $C H I=$ chalcone isomerase; $F 3 H=$ flavanone 3 -hydroxylase; $F 3{ }^{\prime} 5^{\prime} H=$ flavonoid 3'5'-hydroxylase; $D F R=$ dihydroflavonol 4-reductase; $A N S=$ anthocyanidin synthase; UFGT = UDP glucose: flavonoid 3-Oglucosyltransferase; $b H L H=$ basic helix-loop-helix; $W D R=$ WD40-repeat.

Supplemental Table 2. Retention time and spectral data for chlorophylls and carotenoids that were separated by high-performance liquid chromatography from the reference compounds and extracts from the fruit of the paprika cultivars Mavras and Tequila at $20 \mathrm{~d}$ after pollination (DAP) (chlorophylls) or 60 DAP (carotenoids).

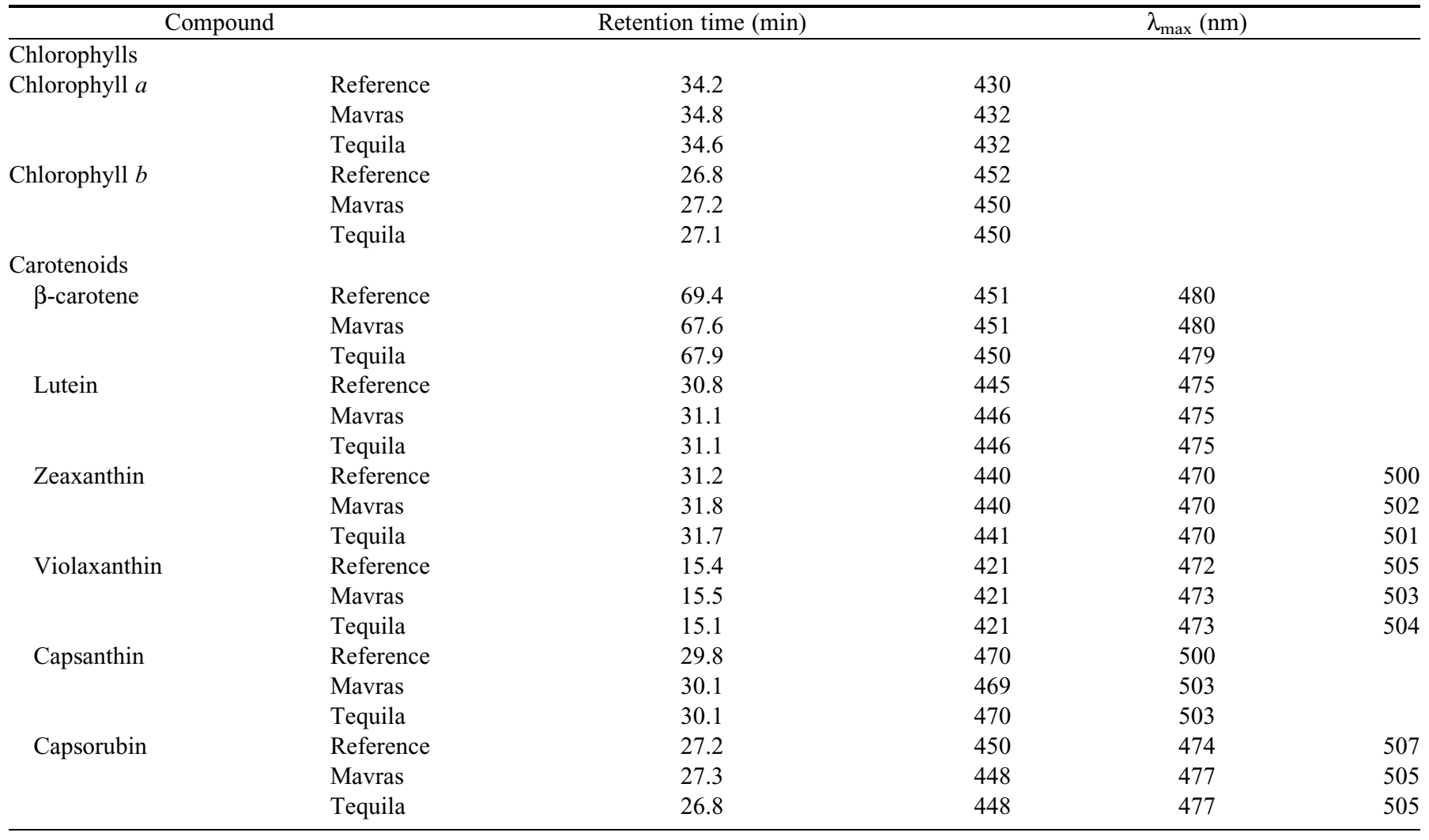

